University of Nebraska - Lincoln

DigitalCommons@University of Nebraska - Lincoln

Faculty Publications: Department of Entomology

Entomology, Department of

1994

Passive Trap for Monitoring Codling Moth (Lepidoptera: Tortricidae) Flight Activity

Thomas J. Weissling

University of Nebraska-Lincoln, tweissling2@unl.edu

Alan L. Knight

Yakina Agricultural Reasearch Laboratory

Follow this and additional works at: https://digitalcommons.unl.edu/entomologyfacpub

Part of the Entomology Commons

Weissling, Thomas J. and Knight, Alan L., "Passive Trap for Monitoring Codling Moth (Lepidoptera: Tortricidae) Flight Activity" (1994). Faculty Publications: Department of Entomology. 327.

https://digitalcommons.unl.edu/entomologyfacpub/327

This Article is brought to you for free and open access by the Entomology, Department of at DigitalCommons@University of Nebraska - Lincoln. It has been accepted for inclusion in Faculty Publications: Department of Entomology by an authorized administrator of DigitalCommons@University of Nebraska - Lincoln. 
SAMPLING

\title{
Passive Trap for Monitoring Codling Moth (Lepidoptera: Tortricidae) Flight Activity
}

\author{
THOMAS J. WEISSLING AND ALAN L. KNIGHT \\ Yakima Agricultural Research Laboratory, USDA-ARS, 3706 W. Nob Hill Boulevard, \\ Yakima, WA 98902
}

\begin{abstract}
J. Econ. Entomol. 87(1): 103-107 (1994)
ABSTRACT A new passive trap, constructed of rigid, clear plastic panes $(0.3 \mathrm{~m}$ by $0.3 \mathrm{~m})$, coated with an STP Oil Treatment film as an adhesive, was developed for monitoring codling moth, Cydia pomonella (L.), movement within and between orchard canopies. Tests showed that the trap was effective in recapturing released codling moth adults, that the adhesive was not attractive to moths, and that the adhesive was still effective after remaining on a trap for $1 \mathrm{wk}$ in the field. Field experiments demonstrated that the passive pane-trap method is as efficient for catching moths as molasses-baited traps but that it is less efficient than pheromone-baited and blacklight traps placed in an orchard at equal densities. However, total capture of moths in plots treated with pane traps increased with trap density.
\end{abstract}

KEY WORDS Cydia pomonella, trapping, behavior

SOUTHWOOD (1978) GROUPED TRAPS by those that catch animals randomly and those that attract animals in some way. Fermenting baits, UV light, and sex pheromones have been used to actively trap male and female codling moths, $C y$ dia pomonella (L.). Trapping has been used to augment control; to assess moth density, phenology, dispersal, and behavior; and to evaluate the success of mass trapping, sterile insect release, and mating disruption. Increased use of pheromone-mediated mating disruption as a management technique for codling moths (Brown et al. 1992, Howell et al. 1992, Barnes et al. 1992) has raised several fundamental questions associated with male and female behavior. Movement of moths within the canopy of individual trees, among tree canopies, and along the edge of orchards needs to be addressed to evaluate the mating-disruption technique more fully. Active traps, however, are not suitable for these studies because active traps elicit a behavioral response by the insect (Muirhead-Thomson 1991). Because of the relatively low density of codling moths in orchards and the large canopy volume that needs to be sampled, a passive trapping method is unlikely to retrieve much information without the deployment of a large number of traps. Thus, a passive trapping method for codling moths must be small, inexpensive, and easily maintained.

Krysan \& Horton (1991) reported on the use of a clear, sticky pane trap to study movement of pear psylla, Cacopsylla pyricola (Foerster). During their study, codling moth adults were occa- sionally found on traps (D. Horton, personal communication). This article reports our evaluation of the sticky-pane trap as a tool to study codling moth adult behavior in the field.

\section{Materials and Methods}

Recapture Efficiency. Sticky-pane traps placed in pheromone-treated and untreated plots were used to determine if traps were effective at recapturing released codling moth adults. Pane traps $(0.3$ by $0.3 \mathrm{~m})$ made of clear, rigid, $0.3 \mathrm{~cm}$ thick plastic were made sticky by painting both sides with a thin coating of STP Oil Treatment (STP, Ft. Lauderdale, FL). Traps remained transparent after the application of STP Oil Treatment. Two 6-mm-diameter holes were drilled in two corners of each pane, and wires were looped through each hole. Traps then could be attached to trees by wrapping wires around tree limbs.

The study was conducted in a mature, unmanaged 'Red Delicious' and 'Golden Delicious' $(4.2 \pm 0.2 \mathrm{~m}$ mean height $\pm \mathrm{SEM})$ apple orchard and in an adjoining 'Bartlett' pear orchard (4.0 \pm $0.2 \mathrm{~m}$ mean height $\pm \mathrm{SEM}$ ) at the USDA Yakima Agricultural Research Laboratory, Yakima, WA. Four plots (3-by-3-tree arrangement, 0.03 ha) separated by $50 \mathrm{~m}$ were established-two were among apple trees (block 1), and two were among pear trees (block 2). Pheromone dispensers (Twist-Tie, Shin-Etsu Chemical, Tokyo, Japan) (625 per ha) were placed in two plots (one each in apple and pear) $2.5 \mathrm{~m}$ above ground. The 
remaining two plots were left untreated. Three pane traps were attached vertically to each tree in each plot, one at each the bottom, middle, and near the top of the tree foliage $(1.53 \pm 0.03$, $2.52 \pm 0.05$, and $3.52 \pm 0.06 \mathrm{~m}$ mean heights \pm SEM). Fifty male and 50 female laboratoryreared moths marked with fluorescent powder (DayGlo Color, Cleveland, $\mathrm{OH}$ ) were released in the center of each plot. Moths were removed from traps with a dissecting probe at daily intervals for 2 or $3 \mathrm{~d}$ after release. This test was repeated three times $(6-8,8-10$, and $14-17 \mathrm{Au}$ gust 1992).

Data were converted to percentage of males and females recaptured per plot, subjected to angular (arcsine [square root $x$ ]) transformation (Steel \& Torrie 1980), and analyzed by the Statistical Analysis System ANOVA procedure (SAS Institute 1985). Untransformed means are reported.

Trap Comparisons. Three arrangements and densities of pane traps were compared with four established active trapping methods used for monitoring codling moth adults to assess relative catch efficiency. Traps were placed within 3-by3-tree plots (apple and pear at the USDA orchard [0.03 ha]). Trap treatments included one pane trap per plot (placed on the center tree), four pane traps per plot (all placed on the center tree), nine pane traps per plot (one on each of nine trees in a plot), one wing trap (Scentry, Buckeye, AZ) per plot baited with a rubber septa loaded with $1 \mathrm{mg}$ of codlemone (placed on the center tree), one wing trap per plot baited with two caged virgin female codling moths ( $1-3 \mathrm{~d}$ old) placed on the center tree, one omnidirectional blacklight trap $(6 \mathrm{~W})$ per plot (placed on the center tree), and one aluminum tray $(23 \mathrm{~cm}$ diameter) per plot baited with $250 \mathrm{ml}$ of a molasses and yeast bait $(1: 9$, molasses:water plus $3.7 \mathrm{~g}$ of yeast liter solution) (placed on the center tree). Pane traps were hung vertically, perpendicular to the axis of the tree's trunk. All traps were hung $\approx 3 \mathrm{~m}$ above ground on the north side of trees, except the four pane-trap treatment in which one trap was hung on each of the four cardinal points of a tree. Plots (separated by at least $12 \mathrm{~m}$ ) were arranged in a randomized complete block design, with four blocks-two in apple trees and two in pear trees. Traps were placed in trees on $10 \mathrm{Sep}-$ tember and rerandomized on 16 September. All trapped moths were removed on $14,17,19$, and 23 September. In total, 3,500 laboratory-reared moths were periodically released during the test to augment the endemic population.

The number of male and female codling moths caught per trap treatment per day were subjected to square root $(x+0.01)$ transformation (Steel \& Torrie 1980) and analyzed by analysis of variance using the Statistical Analysis System general linear models procedure (SAS Institute 1985). Untransformed means are reported. The least significant difference test was used for mean separation where significant $(P<0.05)$ statistical differences occurred.

STP Attractiveness. Delta traps (Trece, Salinas, CA) with STP applied as an adhesive were compared with similar traps treated with TangleTrap (Tanglefoot, Grand Rapids, MI) to determine if STP had an olfactory effect on the capture of codling moths. Delta traps were used instead of pane traps to ensure a directed response by moths rather than a random capture.

The entire inner surface of traps was coated with a thin layer of either adhesive. Rubber septa loaded with $1 \mathrm{mg}$ of codlemone were suspended with a wire inside traps $2.5 \mathrm{~cm}$ below trap tops. These traps were compared with similar traps having blank septa. Treatments included traps treated with Tangle-Trap or STP plus pheromone or blank septa. Traps were suspended $2 \mathrm{~m}$ above ground from apple trees in a mature orchard ('Delicious' and 'Golden Delicious') near Moxee, WA, on 9 September 1992. Treatments were arranged in a completely random design (10 replicates) with $25 \mathrm{~m}$ between traps. All trapped moths were sexed and counted on 15 September.

Data were converted to the number of moths caught per trap per day and subjected to square root $(x+0.01)$ transformation (Steel \& Torrie 1980) before analysis of variance by the Statistical Analysis System ANOVA procedure (SAS Institute 1985). The least significant difference test was used for mean separation where significant $(P<0.05)$ differences occurred. Untransformed means are reported.

Trap Efficiency. Pane traps coated with STP and aged in the field for 1,2 , and 3 wk were compared with freshly coated traps for efficiency in retaining moths that made contact. Traps were suspended $3.0-3.5 \mathrm{~m}$ above ground in mature pear trees at the USDA orchard on 17 and 24 September and on 1 October 1992 (six per date). On 8 October, traps were removed from trees and brought into the laboratory, and six new traps were coated with STP. Traps were suspended individually in random order at one end of a $1.6 \mathrm{~m}$ by $0.6 \mathrm{~m}$ by $0.6 \mathrm{~m}$ (length by width by height) flight tunnel made of 0.6-cm-thick clear acrylic sheeting. Twenty-five codling moths of mixed sex were released at the opposite end. A blacklight behind the test trap provided an attractive stimulus for the moths, and a red lamp directly above the arena provided enough light (4.3 lux) to make observations. The number of moths contacting each trap versus the actual number caught was recorded for $5 \mathrm{~min}$. Both sides of traps aged for 1,2 , and 3 wk were tested.

Data were converted to percentage of moths striking trap surfaces that were retained by the adhesive (both sides were combined). Regression analysis (SAS Institute 1985) was used to 
Table 1. Comparison of active and passive irap treatments for capture of codling moth adults in nine tree plots (3 by 3), 1992

\begin{tabular}{lcc}
\hline \hline $\begin{array}{c}\text { Trap types and trap } \\
\text { treatments per } \\
\text { plot }^{a}\end{array}$ & $\begin{array}{c}\text { Mean } \\
\text { tre. per trap treatment plot } \\
\text { per day } \pm \text { SEM }\end{array}$ \\
\cline { 2 - 3 } & Male & Female \\
\hline 1 Pane-trap & $0.04 \pm 0.02 \mathrm{e}$ & $0.07 \pm 0.04 \mathrm{c}$ \\
4 Pane-traps & $0.21 \pm 0.05 \mathrm{de}$ & $0.29 \pm 0.09 \mathrm{ab}$ \\
9 Pane-traps & $0.60 \pm 0.24 \mathrm{~cd}$ & $0.43 \pm 0.20 \mathrm{a}$ \\
Pheromone-baited & $13.44 \pm 2.5 \mathrm{la}$ & $0.00 \pm 0.00 \mathrm{c}$ \\
Virgin 9-baited & $1.86 \pm 0.69 \mathrm{~b}$ & $0.00 \pm 0.00 \mathrm{c}$ \\
Blacklight trap & $1.02 \pm 0.37 \mathrm{bc}$ & $0.30 \pm 0.15 \mathrm{ab}$ \\
Molasses-baited & $0.07 \pm 0.04 \mathrm{e}$ & $0.11 \pm 0.07 \mathrm{bc}$ \\
\hline
\end{tabular}

a Pane traps $(0.3$ by $0.3 \mathrm{~m}$ ) were clear, rigid plastic $0.3 \mathrm{~cm}$ thick, made sticky by painting both sides with a thin coating of STP Oil Treatment; they were hung vertically within a tree's canopy. Except for the 9-pane-trap-treatment, all traps were placed on the middle tree within plots. For the 9-pane-trap treatment, traps were placed one per tree on each of nine trees.

${ }^{b}$ Means within a column followed by the same letter are not significantly different $(P<0.05$; least significant difference).

determine if the percentage retention of moths was related to the aging period.

\section{Results}

Recapture Efficiency. Pane traps were effective at recapturing released moths, and recapture rates varied between sex and pheromone treatment (mean percentage recapture \pm SEM for males: untreated plots, $24.0 \pm 8.9$; pheromonedisrupted plots, $54.0 \pm 11.0$; for females: untreated plots, $24.3 \pm 3.4$; pheromone-disrupted plots, $16.0 \pm 3.4$ ). The difference between percentage of males recaptured in untreated and pheromone-treated plots was significant $(F=$ 5.36; $\mathrm{df}=1,11 ; P<0.05)$. Although more females were recaptured in untreated than in pheromone-treated plots, the difference was not significant at $P<0.05$.

Trap Comparisons. All traps tested caught codling moth adults, and statistical analyses indicated significant differences among trap treatments (males: $F=77.9$; $\mathrm{df}=6,18 ; P<0.01$; females: $F=7.9$; $\mathrm{df}=6,18 ; P<0.01$ ) (Table 1 ). Significantly more males were caught in plots treated with sex pheromone-baited wing traps than in plots treated with any other trap treatment (Table 1). In addition, significantly more males were caught in plots containing a virgin female-baited wing trap than in plots treated with pane traps and molasses-baited traps. The nine-pane-trap treatment caught significantly more males than the one-pane-trap or molassesbaited-trap treatment. Significantly more females were caught in plots treated with nine-pane traps than in plots with sex pheromone-baited, virgin female-baited, molasses-baited, or one-pane traps. In addition, significantly more females were caught in plots with a light trap than in plots treated with a sex pheromone-baited, female-baited, or one-pane trap. Total capture of moths per plot in plots treated with pane traps increased with trap density (Table 1).

STP Attractiveness. Codling moth males were caught in pheromone-baited delta traps treated with STP and Tangle-Trap. Statistical analysis indicated significant differences among treatments $(F=35.4$; df $=3,27 ; P<0.01$ ). Significantly more males were caught in traps baited with pheromone than in traps baited with blank septa (mean number per trap per day \pm SEM: STP plus pheromone $=2.2 \pm 0.5$, Tangle-Trap plus pheromone $=2.2 \pm 0.5$, STP plus blank septa $=0.0 \pm 0.0$, Tangle-Trap plus blank septa $=0.0 \pm 0.0$ ). There was no significant difference between the number of males caught in pheromone-baited traps treated with TangleTrap or STP. No females were trapped.

Trap Efficiency. Pane traps coated with fresh STP retained almost all moths that made contact. However, the percentage of moths retained on traps decreased linearly with the number of weeks $(x)$ that traps were aged in the field: $y=$ $106.7( \pm 6.8)-32.3( \pm 3.4) x ; r^{2}=0.688 ; P \leq 0.01$

\section{Discussion}

Active trapping methods for codling moth adults include pans containing fermenting baits (usually molasses), light traps, and pheromonebaited traps. One or more of these methods have been used to provide information regarding the position of codling moth activity within a tree's canopy (Yothers 1927, McNally \& Barnes 1981, Riedl et al. 1979, Howell et al. 1990), seasonal activity patterns (Spuler 1930), moth movement (Worthley 1932), timing of flight (Batiste et al. 1973a), and the influence of wind direction and temperature on flight (Worthley 1932, Van Leeuwen 1940 , Batiste et al. 1973b). However, the study of natural flight patterns can easily be disrupted by the use of active trapping methods (Muirhead-Thomson 1991). For example, bait pans show a bias for older, mated codling moth females while light traps tend to catch younger females (Geier 1960). In addition, light traps catch a lower percentage of females than bait pans do (Parrott \& Collins 1934; Worthley \& Nicholas 1937). The greatest bias, however, exists with pheromone-baited traps, which catch only males.

Passive systems used for trapping lepidopteran species include interception traps (Canaday 1987, Lavorel 1988, Alexander \& Carlson 1943) and suction devices (Hosking \& Hutcheson 1987). Interception devices such as the malaise trap are of little value for studying codling moth behavior because they would have to be adapted for use at various heights within the orchard canopy. Suction traps, in turn, are expensive and subject to mechanical failure. Sticky-mesh cages $\left(57 \mathrm{~m}^{3}\right)$ have been used to catch dispersing codling moths (A.L.K., unpublished data) but proved to be difficult to handle 
in the field. Results of this study suggest that sticky-pane traps are a useful tool for passive studies of codling moth behavior. They are compact, inexpensive, easily placed in trees, and easily monitored. In addition, pane traps are effective for catching both male and female moths. Using pane traps placed three per tree in 3-by3-tree plots, we recaptured an average of $16-54 \%$ of released moths. These results are similar to those of VanLeeuwen (1940), who reported recapturing 6-73\% of moths released in an orchard treated with fermenting bait traps placed one per tree. Although pane traps were not as effective at catching moths as blacklight and pheromonebaited traps on a one-to-one basis, our data indicate that increased numbers of moths can be caught on a per-plot basis by deploying more pane traps. This may be of importance when working in orchards with low moth densities.

It is assumed that, because traps are transparent, they cannot be visually perceived by moths. However, males use close range visual orientation to locate potential mates (Hutt \& White 1977, Castrovillo \& Cardé 1980), and accumulation of moths on traps could provide visual cues. In addition, females could release pheromone after they are caught on a trap. For example, Mitchell et al. (1972) reported the capture of female Trichoplusia ni (Hübner) in traps baited with synthetic sex pheromone. Further investigation revealed that trapped males released pheromone which attracted the female moths (Landolt \& Heath 1989). Release of pheromone from captured codling moth females could increase capture of males and possibly repel females that would have otherwise contacted a trap. Frequent sampling of traps and removal of moths should reduce the potential for visual or olfactory orientation to traps, but further studies are needed to address these concerns.

Of the numerous adhesive materials used to coat traps (Southwood 1978, Kalcounis et al. 1992), STP offers several advantages. It is relatively easy to clean off traps, it is transparent when applied to traps, and it remains effective in the field for several days. In addition, STP does not appear to provide olfactory cues to moths. The initial effectiveness of STP-treated pane traps may be decreased by the accumulation of debris such as leaves and insects, whereas the accumulation of wind-borne dust and flow of STP off traps may decrease efficiency through time. To maintain effectiveness, larger debris should be removed when traps are sampled and traps should be cleaned and STP reapplied on a weekly basis.

The passive trapping method described here is being used currently in codling moth studies to assess height of activity, movement into and out of orchards, timing of flight, and increases or decreases in activity associated with application of mating-disruption treatments. Information gained from these studies will be essential for determining behavioral mechanisms underlying successes or failures of codling moth mating disruption techniques. Also, this trap design may have utility in other systems that require a passive trap for behavioral studies of Lepidopteran species.

\section{Acknowledgments}

We thank Bryan Frazer (Agriculture Canada, Vancouver, BC) for suggesting STP as a trap adhesive. We are also grateful to Pete Garza for the use of his orchard and to Dave Horton and Gary Judd for reviewing an earlier version of the article. This study was partially supported by a grant from the Washington State Tree Fruit Research Commission.

\section{References Cited}

Alexander, C. C. \& F. W. Carlson. 1943. A comparison of codling moth captures by bait trap and rotary net. J. Econ. Entomol. 36: 637-8.

Barnes, M. M., J. G. Millar, P. A. Kirsch \& D. C. Hawks. 1992. Codling moth (Lepidoptera: Tortricidae) control by dissemination of synthetic female sex pheromone. J. Econ. Entomol. 85: 12741277.

Batiste, W. C., W. H. Olson \& A. Berlowitz. 1973a. Codling moth: influence of temperature and daylight intensity on periodicity of daily flight in the field. J. Econ. Entomol. 66: 883-892.

1973b. Codling moth: diel periodicity of catch in synthetic sex attractant vs. female-baited traps. Environ. Entomol. 2: 673-676.

Brown, D. F., A. L. Knight, J. F. Howell, C. R. Sell, J. L. Krysan \& M. Weiss. 1992. Emission characteristics of a polyethylene pheromone dispenser for mating disruption of codling moth (Lepidoptera: Tortricidae). J. Econ. Entomol. 85: 910-917.

Canaday, C. L. 1987. Comparison of insect fauna captured in six different trap types in a Douglas-fir forest. Can. Entomol. 119: 1101-1108.

Castrovillo, P. J. \& R. T. Cardé. 1980. Male codling moth (Laspeyresia pomonella) orientation to visual cues in the presence of pheromone and sequences of courtship behavior. Ann. Entomol. Soc. Am. 73: $100-105$

Geier, P. W. 1960. Physiological age of codling moth females (Cydia pomonella [L.]) caught in bait and light traps. Nature (Lond.) 185: 709.

Hosking, G. P. \& J. A. Hutcheson. 1987. Lepidopterous defoliators in a developing Pinus radiata stand. New Zealand J. For. Sci. 17: 331-337.

Howell, J. F., R. S. Schmidt, D. R. Horton, S.U.K. Khattak \& L. D. White. 1990. Codling moth: male moth activity in response to pheromone lures and pheromone-baited traps at different elevations within and between trees. Environ. Entomol. 19: 573-577.

Howell, J. F., A. L. Knight, T. R. Unruh, D. F. Brown, J. L. Krysan, C. R. Sell \& P. A. Kirsch. 1992. Control of codling moth in apple and pear with sex pheromone-mediated mating disruption. J. Econ. Entomol. 85: 918-925.

Hutt, R. B. \& L. D. White. 1977. Mating response to visual stimulus in the male codling moth. Environ. Entomol. 6: 567-568. 
Kalcounis, M. C., R. D. Csada \& R. M. Brigham. 1992. Axle grease as an alternative adhesive for use on sticky traps. Can. Entomol. 124: 561-562.

Krysan, J. L. \& D. R. Horton. 1991. Seasonality of catch of pear psylla Cacopsylla pyricola (Homoptera: Psyllidae) on yellow traps. Environ. Entomol. 20: 626-634.

Landolt, P. J. \& R. R. Heath. 1989. Attraction of female cabbage looper moths (Lepidoptera: Noctuidae) to male-produced sex pheromone. Ann. Entomol. Soc. Am. 82: 520-525.

Lavorel, C. 1988. Les geometrides (Lepidopteres) des haies au Val-de-Travers. Bull. de la oc. Neuchateloise des Sciences Naturelles. 111: 61-65.

McNally, P. S. \& M. M. Barnes. 1981. Effects of codling moth pheromone trap placement, orientation, and density on trap catches. Environ. Entomol. 10: 22-26.

Mitchell, E. R., J. C. Webb \& R. W. Hines. 1972. Capture of male and female cabbage loopers in field traps baited with synthetic sex pheromone. Environ. Entomol. 1: 525-526.

Muirhead-Thomson, R. C. 1991. Trap responses of flying insects. Academic, San Diego, CA.

Parrott, P. J. \& D. L. Collins. 1934. Phototropic responses of the codling moth. J. Econ. Entomol. 27: $370-379$.
Riedl, H., S. A. Hoying, W. W. Barnett \& J. E. DeTar. 1979. Relationship of within-tree placement of the pheromone trap to codling moth catches. Environ. Entomol. 8: 765-769.

SAS Institute. 1985. SAS user's guide: statistics, 5 th ed. SAS Institute, Cary, NC.

Southwood, T.R.E. 1978. Ecological methods. Chapman and Hall, London.

Spuler, A. 1930. Codling moth activity in the Wenatchee Valley as shown by trap records. J. Econ. Entomol. 23: 803-809.

Steel, R.G.D. \& J. H. Torrie. 1980. Principles and procedures of statistics, 2nd ed. McGraw-Hill, New York.

Van Leeuwen, E. R. 1940. The activity of adult codling moths as indicated by captures of marked moths. J. Econ. Entomol. 33: 162-166.

Worthley, H. N. 1932. Studies of codling moth flight. J. Econ. Entomol. 25: 559-565.

Worthley, H. N. \& J. E. Nicholas. 1937. Tests with bait and light to trap codling moth. J. Econ. Entomol. 30: 417-422.

Yothers, M. A. 1927. Summary of three years' tests of trap baits for capturing codling moth. J. Econ. Entomol. 20: 567-575.

Received for publication 1 February 1993; accepted 13 August 1993. 